\title{
KRISIS INDONESIA TAHUN 1997-1998 DALAM BAHASA RUPA KARTUN EDITORIAL SURAT KABAR KOMPAS DAN REPUBLIKA
}

\author{
Noval Sufriyanto Talani ${ }^{1}$, Yasraf Amir Piliang ${ }^{2}$ \\ 1,2Program Studi Doktor Ilmu Seni Rupa dan Desain, FSRD ITB \\ Jalan Ganesha No. 10 Bandung 40123 \\ novalst@ung.ac.id
}

\begin{abstract}
Abstrak: Penggunaan kartun sebagai editorial menjadi hal penting bagi surat kabar untuk menyampaikan opini dan komentar melalui visual. Kartunis memiliki bahasa rupa yang khas dalam menyampaikan opini dan komentarnya, baik untuk menyindir atau mengkritik. Artikel ini untuk mengkaji kartun editorial surat kabar Kompas dan Republika dalam mengungkap krisis yang terjadi di Indonesia pada tahun 1997-1998. Penelitian ini menggunakan metode kualitatif dan teori bahasa rupa dari Primadi Tabrani sebagai perangkat analisis data. Teori ini membagi analisis ke dalam dua langkah, yaitu isi wimba dan cara wimba. Pembahasan mendalam dilakukan pada enam kartun yang dipilih dari 116 kartun editorial yang terkumpul. Kriteria pemilihan kartun berdasarkan keunikan dari peristiwa krisis yang digambarkan dan tipe wacana kartun yang digunakan. Keenam kartun juga mewakili tiga tema (politik, ekonomi dan sosial) dan dua surat kabar yang dikaji. Hasil penelitian menunjukkan bahwa setiap tema menampilkan wimba yang berbeda. Kemampuan kartunis dalam mengolah elemen-elemen visual membuat penampilan krisis dalam kartun lebih dramatis. Kartun non-monolog, monolog, dan dialog adalah jenis kartun yang digunakan oleh kartunis sebagai sarana untuk membawa cerita di dalamnya. Kehadiran karakter sebagai partisipan dan balon kata sebagai bentuk dialog dapat menjadi penanda untuk mengidentifikasi jenis kartun yang digunakan. Melalui Wimba, kartunis dapat mengartikulasikan keberpihakan mereka pada isu yang menjadi sorotan media.
\end{abstract}

Kata kunci: krisis, bahasa rupa, tema, kartun editorial, surat kabar

Abstract: The use of cartoons as editorial is essential for newspapers to convey opinions and comments through visuals. Cartoonists have a distinctive visual language in conveying their opinions and comments, both to satire or criticize. This article examines the editorial cartoons of Kompas and Republika newspapers in uncovering the crisis that occurred in Indonesia in 1997-1998. The research uses qualitative methods and visual language theory from Primadi Tabrani as a data analysis tool. This theory divides analysis into two steps, namely the Wimba content and the Wimba process. The in-depth discussion was carried out on six cartoons selected from 116 editorial cartoons collected. The criteria for selecting cartoons are based on the uniqueness of the crisis events described and the type of cartoon discourse used. The six cartoons also represent three themes (political, economic and social) and two newspapers studied. The results of the study show that each theme displays different Wimba. The ability of cartoonists to process visual elements makes the appearance of the crisis in cartoons more dramatic. Cartoon non-monologues,

${ }^{1}$ Mahasiswa Program Studi Doktor IImu Seni Rupa dan Desain, FSRD ITB, Email: novalst@ung.ac.id ${ }^{2}$ Kelompok Keahlian IImu-ilmu Desain dan Budaya Visual, FSRD ITB, Email: ya_piliang@yahoo.com 
monologues, and dialogues are the types of cartoons used by cartoonists as a means of carrying stories in them. The presence of characters as participants and word balloons as a form of dialogue can be a marker to identify the type of cartoon used. Through Wimba, cartoonists can articulate their alignments to an issue that is in the media spotlight.

Keywords: crisis, visual language, theme, editorial cartoon, newspapers

\section{PENDAHULUAN}

Pengunduran diri Presiden Suharto pada 21 Mei 1998 merupakan klimaks dari krisis multidimensi yang dialami Indonesia sejak pertengahan tahun 1997. Krisis yang diawali oleh krisis moneter yang ditandai dengan melemahnya nilai tukar rupiah terhadap dolar Amerika telah berdampak luas ke persoalan sosial politik. Pemerintah kehilangan kepercayaan rakyat dalam menyelesaikan berbagai persoalan yang dihadapi saat itu. Secara politik, situasi Pemilihan Umum (Pemilu) 1997 yang diwarnai dengan berbagai tindak kekerasan dan kerusuhan hingga membuat situasi dan stabilitas keamanan semakin tidak menentu.

Situasi semacam itu tidak lepas dari pengamatan dan peliputan media massa, baik nasional maupun mancanegara. Selama periode krisis tersebut tentunya media masa khususnya surat kabar telah menyajikan beragam konten yang menggambarkan peristiwa-peristiwa yang terjadi setiap saat. Di antara konten yang digunakan surat kabar adalah kartun editorial. Kartun editorial adalah kartun yang digunakan media pers cetak (surat kabar, majalah, tabloid) bersisi sindiran dan mengomentari peristiwa, berita, atau isu yang menjadi perbincangan hangat di masyarakat (Sunarto, 2005:3-4). Wagiyono Sunarto (2013:135) berpendapat bahwa kartun editorial-yang disebut Sunarto dengan karikatur politik - adalah komentar visual dari seorang kartunis. Pengamatan, pemahaman politik, dan sikap kritis terhadap keadaan masyarakat menjadi dasar baginya untuk membangun komentarnya melalui kartun.

Kartun editorial disebut Sudarta (2018:xxxi) sebagai versi lain dari jurnalistik yang memanfaatkan gambar yang bertema sosial atau politik dan di 
dalamnya bermuatan humor. Dengan demikian, dalam menggambarkan krisis yang terjadi di Indonesia, kartun editorial bukan hanya menampilkan peristiwa apa yang terjadi tetapi juga bagaimana peristiwa digambarkan. Merujuk pada pendapat Sunarto (2013:135), sebuah kartun mengandung keberpihakan kartunis yang didasari oleh konsep dan prinsip yang digunakan untuk bersikap. Di sini menyiratkan bahwa kartun editorial bersifat tidak netral. Dalam menggambarkan krisis yang terjadi di Indonesia tentunya para kartunis memiliki cara dan bahasa yang khas dalam mengungkap dan mengomentari persitiwa yang terjadi.

Pada titik inilah yang menjadi dasar penelitian ini dilakukan untuk mengkaji bahasa rupa kartun editorial dalam menggambarkan krisis yang terjadi di Indonesia tahun 1997-1998. Dengan mengambil kartun editorial surat kabar Kompas dan Republika sebagai objek yang dikaji, penelitian bertujuan untuk mendeskripsikan apa dan bagaimana krisis di Indonesia digambar melalui kartun. Pemilihan Kompas dan Republika didasari oleh latar belakang kedua surat kabar sebagai media masa yang cukup berpengaruh di Indonesia. Selain itu, dari latar belakang sejarah berdirinya, Kompas termasuk surat kabar yang didirikan pada akhir masa Orde Lama sedangkan Republika didirikan pada masa Orde Baru. Perbedaan ini menjadi hal menarik dalam melihat cara kedua surat kabar tersebut menampilkan peristiwa krisis melalui kartunnya.

\section{KAJIAN TEORI}

Bahasa rupa yang digunakan di dalam penelitian ini adalah bahasa rupa yang dikembangkan oleh Primadi Tabrani dalam membaca sebuah gambar. Tabrani (2009:9) dalam teorinya membatasi bahasa rupa pada aspek bercerita dari pada aspek estetis dan simbolis. Konsep penting yang terdapat dalam teori bahasa rupa Tabrani adalah imaji dan tata ungkap. Imaji dan tata ungkap ini menjadi padanan dari kata dan tata bahasa dalam bahasa kata. Selanjutnya, citra dan wimba diperkenalkan Tabrani. Menurutnya, citra adalah imaji dalam khayalan 
sedangkan wimba adalah imaji yang kasat mata. Di dalam bahasa rupa, wimba dibedakan menjadi isi wimba dan cara wimba. Pembedaan ini terletak pada apa yang digambar dan dengan cara apa gambar itu digambarkan. Tabrani (2009) mencontohkan gambar kerbau yang mewakili objek kerbau adalah isi wimba. Sementara cara wimba berhubungan dengan penggambaran objek yang dapat bercerita atau disebut tata ungkap dalam. Jika tata ungkap dalam menceritakan sebuah peralihan tertentu, maka disebut tata ungkap luar. Artinya, di dalam gambar bisa saja terjadi peralihan ruang dan waktu.

Tabrani (2009) menegaskan bahwa gambar yang dikaji dalam bahasa rupa adalah gambar yang representatif, bukan yang abstrak seperti ragam hias dan lainlain. Dengan kata lain, objek kajian bahasa rupa bersifat representasional dan komunikatif. Hal ini ditandai oleh kehadiran objek yang merepresentasikan sesuatu dan susunannya mengandung cerita atau narasi. Dari perspektif bahasa visual menurut Gunter Kress dan Theo van Leuween (2006:41-43), bila sebuah visual berfungsi penuh menjadi sistem komunikasi harus memenuhi persyaratan representasional dan komunikatif. Dengan mengadopsi teori metafungsi bahasa dari Michael Halliday, Kress dan van Leuween menerapkan metafungsi ideasional, interpersonal, dan tekstual. Ketiga metafungsi bahasa inilah yang dapat mengarahkan proses pemaknaan terhadap tata bahasa dari sebuah desain visual.

Gagasan Kress dan van Leuween ini dapat dimanfaatkan dalam analisis nanti yang dielaborasi dengan analisis bahasa rupa Tabrani. Kartun editorial memiliki karakteristik yang khas. Selain memiliki gambar, di dalamnya juga biasa terdapat teks berupa tulisan, baik sebagai label, caption, maupun ujaran. Kembali pada teori bahasa rupa, Tabrani (2009) membagi objek kajian ke dalam tiga rumpun, yaitu media rupa rungu dwimatra dinamis, media rupa rungu dwimatra statis, dan bahasa rupa gambar tunggal. Film, televisi, wayang kulit atau wayang golek termasuk media rupa rungu dwimatra dinamis dan ini paling kompleks dalam kajian bahasa rupa. Slide suara dan wayang beber masuk dalam kategori 
media rupa rungu dwimatra statis sedangkan lukisan, foto, sketsa termasuk kartun editorial masuk dalam rumpun gambar tunggal. Dengan demikian, kajian ini berfokus pada bahasa rupa gambar tunggal kartun editorial surat kabar Kompas dan Republika.

\section{METODE PENELITIAN}

Penelitian ini termasuk ke dalam kategori penelitian kualitatif karena hasilnya berupa uraian-uraian deskriptif dari objek (kartun editorial) yang diteliti. Dengan demikian, analisisnya menggunakan metode deskriptif kualitatif, yaitu cara menuliskan hasil penelitian secara naratif dari pembahasan umum ke khusus guna mendapatkan kesimpulan (Humrotin, 2015:20). Berdasarkan kajian teori di atas, elemen penting dalam analisis bahasa rupa adalah wimba dan tata ungkapan (lihat Gambar 1). Wimba terdiri dari isi wimba dan cara wimba. Keduanya mendeskripsikan apa yang digambar di dalam kartun editorial dan bagaimana gambar itu digambar. Sementara tata ungkapan hasil dari deskripsi wimba untuk mengungkap cerita di dalam kartun editorial. Penerbitan kartun editorial yang membahas tema yang sama dapat dipahami sebagai sebuah gambar bercerita dalam ruang dan waktu yang berbeda. Selain melihat tema, tata letak dari setiap elemen rupa di dalam kartun editorial dapat mengungkap cerita pada suatu ruang dan waktu yang dipadatkan dalam sebuah gambar tunggal. Dengan demikian, tata ungkapan tidak hanya bergantung pada tematik semata tetapi juga tampak melalui tata letak elemen rupa di dalam kartun. Tentu kartun-kartun yang dianalisis fokus pada kartun yang mengungkap krisis yang terjadi di Indonesia tahun 1997-1998. 


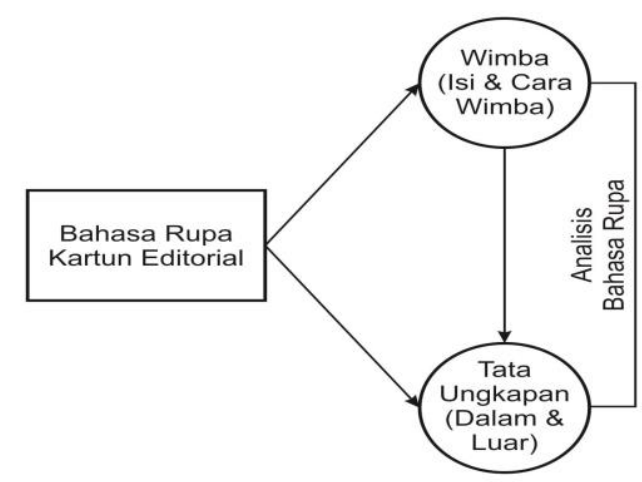

Gambar 1 Kerangka Analisis Bahasa Rupa

(Sumber: Kontruksi penulis)

\section{HASIL DAN DISKUSI}

Berdasarkan data kartun editorial yang terkumpul diketahui bahwa selama periode 1997 hingga Mei 1998, surat kabar Kompas dan Republika telah menerbitkan kartun sebanyak 116 kartun yang mengomentari berbagai peristiwa yang terjadi saat itu (lihat Tabel 1). Secara tematik, kartun tersebut dibagi ke dalam tiga tema utama, yaitu tema politik, ekonomi, sosial termasuk tema budaya. Dari 62 kartun editorial yang diterbitkan Kompas, 21 kartun mengangkat tema politik, 18 kartun bertema ekonomi, 21 kartun bertema sosial budaya termasuk isu tentang hukum dan keadilan, dan 2 kartun bertema luar negeri. Sementara Republika menerbitkan 54 kartun editorial yang terdiri dari 16 kartun bertema politik, 14 kartun bertema ekonomi, dan 24 kartun mengangkat tema sosial budaya. Bila melihat data yang ada, kedua surat kabar banyak menyoroti persoalan-persoalan yang terkait dengan ekonomi dan politik. Persoalan politik yang diangkat berkisar pada isu-isu tentang pemilihan umum tahun 1997 dan persoalan ekonomi terkait dengan krisis moneter yang melanda Indonesia. 
Tabel 1 Frekuensi Penerbitan Kartun Editorial Selama Periode 1997-1998

\begin{tabular}{ccc}
\hline \multirow{2}{*}{ Surat Kabar } & \multicolumn{2}{c}{ Kartun Editorial } \\
\cline { 2 - 3 } & Periode 1997 & Periode 1997 \\
\hline Kompas & 42 & 20 \\
\hline Republika & 44 & 10 \\
\hline Jumlah & $\mathbf{8 6}$ & $\mathbf{3 0}$
\end{tabular}

Dari uraian di atas, dipilih enam kartun editorial yang akan dibahas secara mendalam dari sudut pandang bahasa rupa. Kartun yang dipilih adalah rupa kartun yang menggambarkan kompleksitas krisis yang terjadi di Indonesia dan keunikan cara penggambarannya berdasarkan jenis-jenis wacana kartun. Masing-masing tema diambil dua kartun untuk mewakili bahasa rupa dari kartun editorial Kompas dan Republika. Pembahasan dibagi ke dalam tiga aspek persitiwa, yaitu tata ungkap rupa yang menggambarkan krisis politik, ekonomi, dan sosial. Uraiannya didasarkan pada wimba (isi dan cara wimba) yang dianalisis.

\section{Tata ungkap rupa dalam krisis politik}

Ada dua kartun editorial yang dipilih untuk dibahas lebih mendalam. Kedua kartun tersebut mengomentari isu-isu politik, yaitu peristiwa-peristiwa yang terjadi selama musim kampanye Pemilu tahun 1997 (Gambar 2).
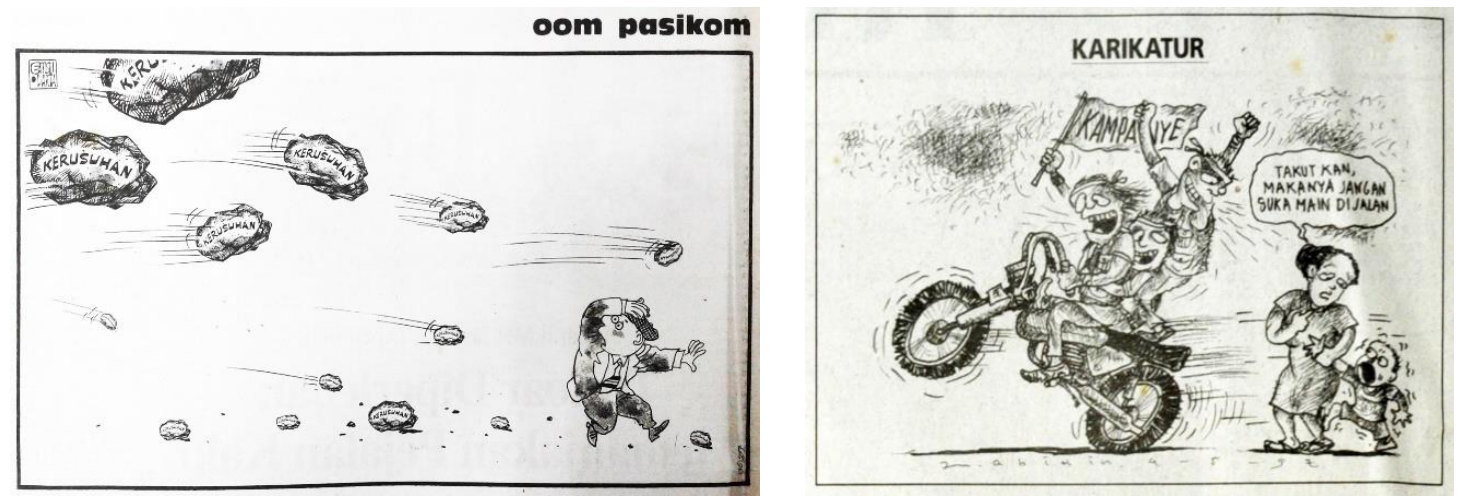

Gambar 2 Kerusuhan Selama Kampanye Pemilu 1997 (kiri) dan Gambar Aksi Ugal-ugalan Peserta Kampanye (kanan) sumber: Kompas, 18/6/1997 dan Republika, 4/5/1997 


\section{Isi wimba}

Kedua kartun editorial di atas dibuat dalam panel tunggal dan masingmasing kartun menampilkan figur manusia. Kartun editorial surat kabar Kompas pada Gambar 1 menampilkan figur Oom Pasikom yang berlari menghindari lemparan batu. Di masing-masing batu terdapat label "Kerusuhan". Figur Oom Pasikom adalah figur rekaan ciptaan kartunis Kompas G.M. Sudarta dengan ciri khas memakai topi, mengenakan jas, dan memiliki karakter wajah berbentuk bulat. Pada kartun editorial yang diterbitkan Republika menggambarkan lima orang figur yang menjadi partisipan. Tiga orang figur mengendarai sebuah sepeda motor dengan roda depannya terangkat, masing-masing figur mengenakan ikat kepala. Tangan kanan sang pengendara memegang bendera yang bertuliskan "Kampanye" dan tangan kirinya memegang setir motor. Sosok paling belakang menoleh ke arah figur seorang ibu dan anaknya sambil mengangkat kedua tangannya. Sambil menoleh ke arah anaknya yang terlihat ketakutan, sang ibu berujar "Takut kan, makanya jangan suka main di jalan". Hal ini terlihat dari gambar balon kata yang berada tepat di atas kepala sang ibu. Di bagian latar belakang terdapat garis-garis yang tak beraturan yang membentuk arsiran kasar pada kartun.

\section{Cara wimba}

Kedua kartun menggambarkan sebuah peristiwa yang cukup dramatis dalam menceritakan situasi yang terjadi selama musim kampanye Pemilu 1997. Kartun editorial surat kabar Kompas bercerita tentang banyaknya kerusuhan yang terjadi selama musim kampanye. Objek digambar dengan menggunakan teknik perspektif satu titik hilang. Ekspresi figur Oom Pasikom menunjukkan sebuah keterkejutan terhadap peristiwa kerusuhan yang terjadi. Posisi sambil berlari dengan tangan kanan menutupi bagian kepala memberi pesan untuk menghindar 
agar tidak terjebak di tengah-tengah kerusuhan sebab peristiwanya masih terus berlangsung. Penggambaran kartun secara long shot memperlihatkan keseluruhan peristiwa yang terjadi di dalamnya. Tipografi dari tulisan "Kerusuhan" yang digunakan berjenis script atau tulisan tangan manual dengan karakteristik san serif agar memudahkan khalayak mengidentifikasi pesan dalam teks.

Kartun editorial surat kabar Republika juga bercerita tentang situasi di masa kampanye. Perbedaan mendasar dengan kartun editorial Kompas adalah cerita mengenai tindakan ugal-ugalan yang dilakukan peserta kampanye. Kartunis menggambar objek di dalamnya dengan teknik tiga perempat tampak depan dengan sudut pandang tampak samping. Mengendarai motor bertiga dengan roda depan terangkat menguatkan cerita ketakutan seorang anak dan tindakan ugalugalan yang dilakukan peserta kampanye. Tipografi di dalamnya menggunakan jenis script dan berkarakteristik sans serif. Gambar hitam putih dari kartun menghadirkan kontras objek-objek yang digambar untuk membedakan objek dan latar belakangnya.

Garis adalah elemen rupa dasar yang sangat berperan dalam mendramatisir peristiwa, baik digunakan sebagai arsir maupun efek gerakan. Garis sebagai efek gerakan membawa pengamat ke dalam suasana yang digambarkan seolah-oleh sedang berlangsung. Cohn (2007:48) menyebut garis demikian dengan morfem terikat (bound morphemes). Karena garis untuk efek gerakan tidak memiliki makna lain selain garis saja seperti garis lurus atau lengkung. Bila garis yang menjadi efek gerakan dari batu yang dilempar atau motor berjalan dihilangkan, maka tidak menyampaikan makna pergerakan pada kedua objek itu. Batu seolah mengapung dan motor terkesan berhenti.

Berfungsinya elemen garis sebagai efek gerakan mengindikasikan adanya peralihan ruang dan waktu atau disebut Tabrani (2009) dengan tata ungkapan luar. Gambar batu yang tergeletak dan sedang bergerak melayang menunjukkan adanya peristiwa kerusuhan yang telah terjadi dan masih berlangsung. Begitu pula 
dengan garis kecepatn pada roda motor bagian belakang menunjukkan bahwa motor tersebut telah melewati seorang ibu bersama anaknya. Kehadiran sosok orang di dalamnya menjadi partisipan yang diwakili. Menurut Kress dan van Leuween (2006:48), partisipan yang diwakili adalah partisipan yang menjadi subjek komunikasi, yaitu orang yang diwakili di dalam gambar. Dengan kata lain, mewakili orang yang terlibat dalam peristiwa kampanye.

Meskipun di dalam kartun terdapat figur orang tidak berarti kartun itu berjenis kartun dialog. Pembedaan jenis kartun dapat dilihat melalui wacananya. Ada tiga tipe wacana kartun menurut Wijana (2004:266), yaitu tipe wacana non monolog (tanpa dialog), monolog, dan dialog. Kartun non-monolog adalah kartun tanpa interaksi. Kehadiran tokoh di dalam kartun bersifat opsional sehingga keberadaannya bisa ditampilkan atau tidak. Untuk kartun monolog dicirikan oleh adanya balon kata atau pernyataan dari seorang tokoh di dalamnya. Bila di dalam kartun terdapat dua tokoh atau lebih dan masing-masing tokoh mengeluarkan pernyataan, maka kartun itu termasuk jenis katun dialog. Dalam bahasan ini, kartun editorial Kompas termasuk kartun non-monolog sedangkan kartun editorial Republika termasuk kartun monolog. Meskipun dalam wimba terdapat lebih dari satu tokoh, akan tetapi hanya tokoh sang ibu yang mengeluarkan pernyataan yang ditujukan kepada anaknya sebagai peringatan untuk tidak bermain dijalan.

\section{Tata ungkap rupa dalam krisis ekonomi}

Pada Gambar 3 dan 4, kartunis berupaya menceritakan krisis ekonomi yang terjadi pada tahun 1997 melalui panel tunggal. Kartun-kartun tersebut merupakan metafora dari krisis ekonomi yang melanda Indonesia dan juga negara-negara ASEAN. Di sini kartunis masih memanfaatkan gelap terang sebagai kontras yang membedakan antara objek dan latar belakangnya. Keduanya berlatar belakang cerah sehingga objek yang digambar menjadi jelas dan menarik perhatian. 

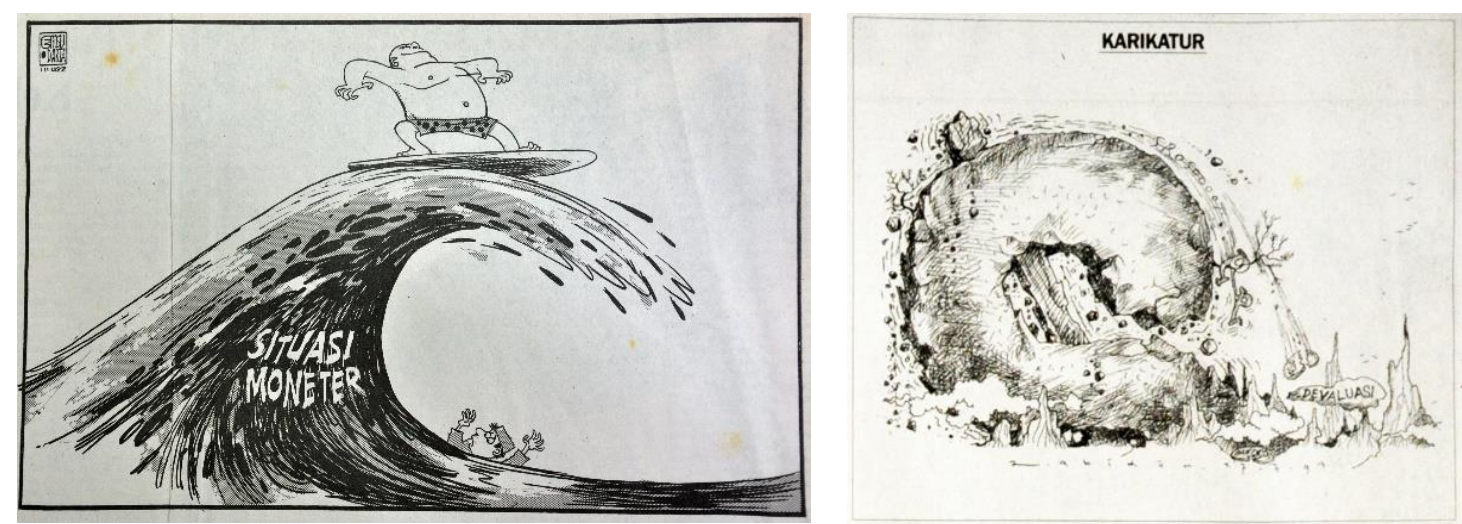

Gambar 3 Berselancar Pada Saat Krisis Moneter (kiri) dan Gambar Devaluasi Rupiah Terhadap Dolar (kanan)

sumber: Kompas, 1/11/1997 dan Republika, 27/7/1997

\section{Isi Wimba}

Pada Gambar 3, kartun editorial Kompas terdiri dua orang partisipan, gelombang air, papan selancar dan tulisan "Situasi moneter". Seorang partisipan bertubuh gendut dengan perut buncit tanpa mengenakan baju dan hanya bercelana pendek bercorak titik-titik sedang menaiki sebuah papan selancar mengikuti gelombang ombak. Kedua tangannya terangkat dan posisi wajah menengadah ke atas. Seorang partisipan lagi hampir tenggelam. la mengenakan baju lengan panjang dan peci dengan mata yang melirik pada tulisan "Situasi moneter" yang tertera di bagian tengah dari gelombang. Terdapat efek gradasi dari terang ke gelap di bagian gelombang dan papa seluncur. Pada kartun editorial Republika terdapat gambar simbol dolar (\$) yang menyembul keluar dari dalam tanah. Terdapat dua pohon yang telah kering, koin yang patah tertulis "Peso" dan "Bath", huruf "Rp" yang tersangkut di pohon, terdapat tulisan "Srosoooot", dan "Devaluasi".

\section{Cara Wimba}

Kedua kartun editorial bercerita tentang situasi krisis moneter dengan menampilkan metafora suasana yang berbeda. Metafora pada kartun editorial 
Kompas membangun cerita situasi moneter dengan suasana pantai dengan seseorang yang menikmati gelombang dengan berselancar. Sementara orang lainnya hampir tenggelam berada di bawah ombak besar. Tulisan "Situasi moneter" dibuat dari jenis tipografi script dengan karakter san serif. Adanya gradasi dari terang ke gelap pada gelombang, selain memberi kesan dimensi juga membuat kesan mencekam bagi orang di bawahnya. Tata ungkapan dalam dari wimba ini menceritakan adanya orang yang memanfaatkan krisis moneter. Konteks kartun ini mengomentari tindakan para spekulan yang memanfaatkan krisis dengan berbagai spekulasi termasuk memanfaatkan pelemaham rupiah terhadap mata uang asing. Kartun editorial Republika memperjelas cerita tentang terjadinya devaluasi. Kemunculan simbol dolar dari dalam tanah telah menimbulkan kerusakan disekelilingnya. Artinya, menguatnya mata uang dolar berdampak pada pelemahan mata uang lain seperti mata uang Rupiah, Peso, dan Baht.

Koin (mata uang Filipina) "Peso" tergelincir jatuh dan terbelah dua. Begitu pula dengan koin (mata uang Thailand) "Bath" yang tergeletak dalam kondisi terbelah dua. Sementara mata uang Rupiah (Rp) masih tersangkut disebatang pohon kering. Tulisan "Devaluasi" dapat dipahami sebagai caption dari kartun yang memberi petunjuk tata ungkapan dalam bahwa kartun tersebut becerita tentang penurunan nilai tukar mata uang (Rupiah, Peso, Baht) terhadap dolar Amerika. Di sini yang mengalami krisis moneter bukan hanya Indonesia tetapi juga negara-negara ASEAN lainnya seperti Filipina dan Thailand. Penandanya dalah hadirnya jenis mata uang "Peso" dan "Bath". Garis-garis kecepatan dan batu-batu yang terjatuh menjadi petunjuk tata ungkapan luar dari kartun sebagai peralihan (ruang dan waktu) simbol dolar dari dalam tanah bergerak menyembul keluar. Sementara peralihan pada kartun editorial Kompas dapat diamati melalui penempatan partisipan di dalam wimba, satu orang berada di atas sedangkan lainnya berada di bawah. Begitu pula dengan arah gelombang air dari kiri ke kanan 
dapat menjadi petunjuk dari perubahan situasi. Perbedaan kedua kartun terletak pada keberadaan partisipan dan teknik penggambaran dengan posisi long shot dan medium shot. Namun, keduanya sama-sama membangun cerita krisis ekonomi yang cukup dramatis. Kedua kartun dapat dikategorikan ke dalam tipe kartun non monolog karena tulisan di dalamnya hanya berfungsi menjadi caption dan label.

\section{Tata ungkap rupa dalam krisis sosial}

Tidak jauh berbeda dengan kartun-kartun sebelumnya, pada Gambar 5 dan 6, kartunis masih memanfaatkan panel tunggal dalam membangun cerita melalui wimba. Penggunaan teks tulisan memegang peran penting agar konteks yang dibicarakan di dalam kartun bisa diketahui atau bahkan dipahami. Persoalan sosial yang terkait dengan isu tenaga kerja Indonesia dan kritik yang semakin mengemuka terhadap pemerintah Orde Baru menjadi pilihan Kompas dan Republika untuk dikomentari.
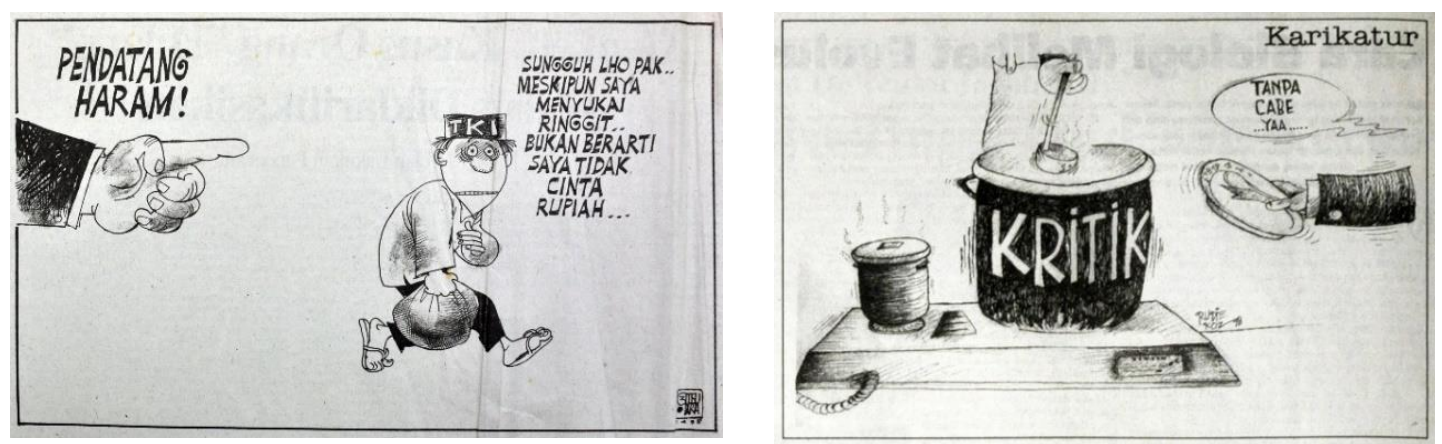

Gambar 4 Persoalan Tenaga Kerja Indonesia (TKI) (kiri) dan Gambar Menghadapi Kritik (kanan) sumber: Kompas, 1/4/1998 dan Republika, 8/3/1998

\section{Isi Wimba}

Di dalam wimba kartun editorial Kompas (Gambar 4) terdapat gambar potongan tangan sebelah kiri sedang menunjuk dan memakai jas berwarna gelap serta tulisan "Pendatang haram!". Disebelahnya terdapat gambar seorang 
partisipan sedang berjalan, memakai baju lengan panjang dan celana panjang hitam serta berpeci dengan tulisan "TKI", wajah bulat, mulut datar, mata terbelalak, badan membungkuk dan tangan kanan membawa buntalan kain serta memakai sandal jepit. Terdapat tulisan "Sungguh Iho pak... meskipun saya menyukai ringgit... bukan berarti saya tidak cinta rupiah...". Sementara kartun editorial Republika terdapat gambar kompor gas, panci kecil, panci besar tertulis "Kritik", di atasnya ada gambar potongan badan dan tangan memegang sendok kuah, gambar potongan tangan sebelah kanan memakai jas dan memegang piring, dan gambar balon kata dengan tulisan "Tanpa cabe ...уа...".

\section{Cara Wimba}

Ada dua wimba penting di dalam kartun editorial Kompas, yaitu gambar potongan tangan kiri bersama tulisan di atasnya dan gambar partisipan yang sedang berjalan, terlihat seluruh tubuhnya termasuk tulisan di hadapannya. Dengan kata lain, gambar tangan dibuat close up dan gambar figur dibuat long shot. Dalam semiotika, gambar close up tangan disebut dengan tanda metonim, yaitu interaksi tanda dengan mengasosiasikannya dengan tanda lain dan di dalamnya terdapat hubungan bagian dengan keseluruhan (Piliang, 2004:194). Artinya, wimba ini dapat dipahami sebagai bagian dari keseluruhan tubuh seseorang. Close up tangan mewakili kehadiran seorang sosok lain di dalam kartun yang membangun dialog dengan partisipan lain. Posisi telunjuk tangan yang mengarah pada sosok di depannya menjadi petunjuk bahwa tulisan "Pendatang haram" ditujukan kepadanya.

Sosok yang disebut "pendatang haram" tiada lain adalah partisipan yang mewakili tenaga kerja Indonesia. Tulisan "TKI" dibagian peci yang dikenakan sang tokoh menjadi label untuk patisipan. Ini menguatkan pesan bahwa yang dituduh pendatang haram itu adalah para TKI. Perbedaan pakaian yang dikenakan partisipan anonim dengan sosok TKI adalah nilai sosial atau status yang 
ditunjukkan oleh pakaian dan fashion (Barnard, 2006:86). Tata ungkapan dalam dari wimba tersebut bercerita tentang persoalan yang dihadapi TKI di Malaysia. Hadirnya kata "Ringgit" yang notabenenya merupakan mata uang Malaysia menjadi petunjuk bahwa pihak Malaysia menuduh TKI sebagai pendatang haram. Kartun ini merupakan komentar terhadap peristiwa dan berita mengenai kasus TKI ilegal yang melarikan diri dari kamp di Malaysia dan mencari suaka ke UNHCR (Kompas, 31/03/1998). Cara wimba dalam kartun menunjukkan sebuah keberpihakan kartunis. Wimba telunjuk tangan memberi pesan bahwa TKI itu diusir bukan melarikan diri. Ada pembelaan kartunis terhadap TKI. Melalui perbedaan wimba telunjuk tangan dan partisipan TKI membuat tata ungkapan luar dari wimbanya adalah pengusiran TKI yang dilakukan otoritas di Malaysia. Ungkapan partisipan TKI "Sungguh Iho pak... meskipun saya menyukai ringgit... bukan berarti saya tidak cinta rupiah..." menunjukkan adanya sebuah semangat nasionalisme yang digambarkan kartunis. Kalimat "bukan berarti saya tidak cinta rupiah" menunjukkan hal itu. Kartun ini bukan hanya menyindir otoritas Malaysia tetapi juga menyindir pemerintah Indonesia dalam menangani kasus TKI.

Kartun editorial Republika menjadikan wimba panci besar yang tertulis "Kritik" sebagai pusat perhatian. Di sampingnya terdapat panci kecil. Garis-garis yang terdapat di atas panci menjadi efek dari uap untuk menandakan bahwa isi di dalamnya panas. Apalagi bagian bawah dari panci besar masih meperlihatkan nyala api. Ada tangan seseorang yang sedang memegang sendok kuah seolah-olah baru mengambil isi di dalam panci dan akan menuangkannya ke dalam piring yang dipegang partisipan anonim. Muncul pernyataan "Tanpa cabe... ya...." melalui wimba balon kata. Pernyataan itu dapat diasosiasikan berasal dari partisipan anonim yang memegang piring. Partisipan anonim yang memegang sendok kuah merupakan subjek yang dituju oleh penyataan tersebut. Di sini kartun masih menggunakan jenis tipografi script yang berkarakteristik sans serif agar pesan verbal yang disampaikan mudah terbaca. 
Kartunis membuat kehadiran para partisipan secara anomin dan tanda kehadirannya hanya diwakili oleh metonim tangan yang memegang sendok kuah dan piring. Bila mengidentifikasi pakaian yang dikenakan oleh partisipan yang memegang piring dapat diketahui bahwa partisipan tersebut memakai kemeja berwarna terang dan mengenakan jas berwarna gelap. Hal ini terlihat dari gambar pakaian yang dibuat bersusun. Keseluruhan wimba ini membangun tata ungkapan dalam sebagai cerita dari kritik yang ditujukan kepada pemerintah dan lembaga legislatif. Kelompok-kelompok kritis menuntut dilakukannya pembaruan politik dan reformasi disegala bidang. Kemampuan pemerintah dalam menangani krisis moneter yang melanda Indonesia sejak tahun 1997 terus menjadi sasaran kritik. Bila melihat edisi penerbitan kartunnya bertepatan dengan berlangsungnya Sidang Umum Majelis Permusyawaratan Rakyat (SU MPR) yang salah satu agendanya adalah memilih presiden dan wakil presiden. Tulisan "Tanpa cabe ...ya..." dibalon kata merupakan ungkapan satire yang dibuat kartunis untuk menyindir sikap pemerintah Orde Baru yang anti kritik. Tulisan ini juga dapat dianggap sebagai peringatan kepada para pengkritik agar tidak menyampaikan kritik pedas kepada pemerintah. Nantinya kritik pedas itu dapat dianggap pemerintah Orde Baru sebagai tindakan subversi.

Kritik pedas itu tidak lain adalah tuntutan reformasi total yang memanfaatkan momentum SU MPR. Para anggota legislatif dituntut untuk melakukan regenerasi kepemimpinan nasional melalui pemilihan presiden dan wakil presiden pada SU MPR atau setidaknya memilih wakil presiden dan membentuk kabinet yang kredibel mengatasi krisis. Sisi peralihan yang membangun tata ungkapan luar adalah tindakan memberi dan menerima. Artinya, tangan yang memegang sendok kuah dapat dipahami sebagai tindakan memberi sesuatu sedangkan tangan memegang piring adalah pihak yang menerima. Dengan demikian, ruang dan waktu terjadinya peristiwa terletak pada pengkritik dan yang dikritik. Ada ruang dan waktu bagi para pengkritik melayangkan kritiknya 
dan ada pula ruang bagi pemerintah atau lembaga legislatif untuk menerima kritik. Merujuk pada serangkaian wimba dari kedua kartun dapat diidentifikasi bahwa kartun editorial Kompas berjenis kartun dialog sedangkan kartun Republika tergolong kartun monolog.

\section{KESIMPULAN}

Krisis yang melanda Indonesia sejak tahun 1997-1998 yang diungkap melalui bahasa rupa kartun editorial surat kabar Kompas dan Republika dapat memberi gambaran tentang peristiwa yang terjadi saat itu. Wimba yang dihadirkan membangun tata ungkap rupa yang beragam. Pengolahan elemen rupa dasar yang apik mampu menciptakan suasana krisis yang digambarkan begitu dramatik. Ada perbedaan antara surat kabar Kompas dan Republika dalam menceritakan krisis yang terjadi, baik krisis politik, ekonomi, dan sosial ke dalam wimba kartun editorial. Tetapi mayoritas kartun digambar menggunakan panel tunggal. Pemanfaatan panel tunggal dalam membangun cerita yang kompleks menjadi sederhana menuntut kepiawaian kartunis dalam mengolah rupa dan menyampaikan pesan secara efektif. Biasanya kartunis membuat gambar langsung masuk pada pokok persoalan sehingga secara kontekstual memudahkan khalayak mengidentifikasi peristiwa yang digambarkan. Untuk menunjang kemudahan khalayak dalam membaca dan memahami pesan verbal, rata-rata kartunis menggunakan jenis tipografi script atau tulis tangan manual dengan karakteristik san serif agar mudah terbaca.

Selain itu, kehadiran para partisipan yang diwakili akan mengarahkan perhatian khalayak kepada tokoh yang dimaksud di dalam kartun. Para partisipan dapat memainkan peran-peran sosial mereka; misalnya, berperan sebagai pejabat, rakyat, pelaku, atau berperan menjadi korban. Di samping peran sosial, identitas sosial para partisipan juga dapat diidentifikasi melalui label yang dibuat kartunis dan/atau pakaian yang dikenakan oleh para partisipan. Kartun editorial 
yang memiliki balon kata menghasilkan bahasa rupa yang berbeda dengan kartun yang tanpa balon kata. Kehadiran balon kata di dalam kartun dapat membantu untuk mengidentifikasi jenis kartun yang tergolong kartun non-monolog, monolog, atau dialog. Bila kartun tanpa kehadiran balon kata, keberadaan label atau caption menjadi penting. Sementara untuk kartun yang sama sekali tidak memiliki teks (tulisan), kekuatan gambar lebih diandalkan dan tampilan ekspresi sangat berperan di situ. Selain itu, keberpihakan kartunis atau medianya dapat tercermin melalui tampilan wimbanya. Lebih tepatnya tercermin melalui cara wimba atau cara gambar itu digambarkan.

Melalui hasil penelitian ini diharapkan dapat memberi pemahaman bahwa secara teoretis, penerapan kajian bahasa rupa pada gambar tunggal kartun editorial dapat menambah khazanah penelitian di bidang komunikasi visual. Sementara pada tataran praktis, kajian ini dapat memberi gambaran kepada para mahasiswa seni rupa dan desain mengenai teknik para kartunis Kompas dan Republika dalam menggambarkan suatu peristiwa.

\section{UCAPAN TERIMA KASIH}

Penulis mengucapkan terima kasih kepada Kementerian Riset Teknologi dan Pendidikan Tinggi (Kemristekdikti) RI khususnya Direktorat Riset dan Pengabdian Kepada Masyarakat yang telah mendanai penelitian ini melalui skema Hibah Penelitian Disertasi Doktor (PDD) tahun anggaran 2018.

\section{DAFTAR PUSTAKA}

Barnard, M., 2006. Fashion Sebagai Komunikasi: Cara Mengomunikasikan Identitas Sosial, Seksual, Kelas, dan Gender (terj) Idi Subandy Ibrahim dan Yosal Iriantara. Yogyakarta: Jalasutra. 
Cohn, N., 2007. A Visual Lexicon. The Public Journal of Semiotics, 1 (1), 35 - 56. Tersedia di http://www.visuallanguagelab.com/P/visuallexicon.pdf [20 Mei 2018].

Humrotin, 2015. Kajian Bahasa Rupa Kartun Komik Benny Racmadi dalam Buku PR Buat Presiden. Jurnal Dekave, 8, 19-29.

Kress, G. dan van Leuween, T., 2006. Reading Images: The Grammar of Visual Design. New York: Routledge.

Piliang, Y.A., 2004. Semiotika Teks: Sebuah Pendekatan Analisis Teks. Mediator, 5 (2), 189-198. Tersedia di https://ejournal.unisba.ac.id/index.php/mediator/article/ view/1156/715 [02 Maret 2017].

Sudarta, G.M., 2018. Berteriak dalam Bisikan: 50 Tahun Oom Pasikom. Jakarta: Kompas.

Sunarto, P., 2005. Metafora Visual Kartun Editorial Pada Surat Kabar Jakarta 1950- 1957, Disertasi Program Doktor (tidak diterbitkan), Institut Teknologi Bandung.

Sunarto, W., 2013. Perang Kartikatur: Mengangkat dan Menjatuhkan Soekarno, Tinjauan Sejarah 1955-1967. Jakarta: Pascasarjana IKJ.

Tabrani, P., 2009. Bahasa Rupa. Bandung: Kelir.

Wijana, I.D.P., 2004. Kartun: Studi Tentang Permainan Bahasa. Yogyakarta: Ombak.

Sumber Gambar:

Gambar 2 (kiri) Kartun editorial Kompas edisi Rabu, 18 Juni 1997.

(kanan) Kartun editorial Republika edisi Minggu, 4 Mei 1997.

Gambar 3 (kiri) Kartun editorial Kompas edisi Sabtu, 1 November 1997.

(kanan) Kartun editorial Republika edisi Minggu, 27 Juli 1997.

Gambar 4 (kiri) Kartun editorial Kompas edisi Rabu, 1 April 1998.

(kanan) Kartun editorial Republika edisi Minggu, 8 Maret 1998. 